\title{
DISTRIBUCIÓN ESPACIAL DEL REGISTRO ARQUEOLÓGICO EN LA UNIDAD DE PAISAJE TERRAZAS, CUENCA MEDIA DEL RÍO COYLE (PROVINCIA DE SANTA CRUZ, ARGENTINA)
}

\author{
FLAVIA CARBALLO MARINA*, JUAN B. BELARDI" Y JOSÉ L. SÁENZ*
}

\begin{abstract}
RESUMEN
Como resultado de estudios de impacto ambiental sobre el registro arqueológico se suma nueva información sobre la unidad de paisaje Terrazas, cuenca media del río Coyle (provincia Santa Cruz), principalmente en el interfluvio río Coyle - río Santa Cruz. El análisis se centraliza sobre la distribución espacial del registro arqueológico en superficie, en especial materiales líticos relevados en las diferentes geoformas (terrazas, cañadones y cuencas endorreicas) que componen la unidad de paisaje. El estudio -cualitativo y cuantitativo- se focaliza sobre las densidades y clases artefactuales y las materias primas líticas. La evidencia indica que en las distintas geoformas se habrían desarrollado los mismos tipos de actividades que se relacionarían con el aprovisionamiento de rocas y actividades de talla. No obstante, las densidades artefactuales muestran diferencias en su intensidad, destacándose las cuencas endorreicas. El registro de altas frecuencias de raspadores de vidrio junto con dos nuevas dataciones radiocarbónicas ubica a las poblaciones humanas hacia finales del Holoceno tardío. La presencia de moluscos de procedencia atlántica y artefactos de obsidiana sugiere la interrelación con espacios ubicados hacia el norte, este y oeste. La unidad de paisaje Terrazas habría sido utilizada de manera relativamente homogénea a lo largo del tiempo, indicando una baja intensidad de uso humano vinculada con estrategias de movilidad residencial y con la circulación entre las cuencas de los ríos Santa Cruz y Gallegos.
\end{abstract}

PALABRAS CLAVE: Unidad de paisaje Terrazas, cuenca media del río Coyle, Holoceno tardío, cazadores recolectores, distribuciones artefactuales, uso del espacio.

\footnotetext{
Universidad Nacional de la Patagonia Austral. Unidad Académica Río Gallegos. Campus Universitario, Avda. Gregores y Piloto Lero Rivera s/n. (9400) Río Gallegos, Santa Cruz, Argentina.

* Universidad Nacional de la Patagonia Austral. Unidad Académica Río Gallegos. CONICET. Campus Universitario, Avda. Gregores y Piloto Lero Rivera s/n. (9400) Río Gallegos, Santa Cruz, Argentina.
} 


\section{SPATIAL DISTRIBUTION OF ARCHAEOLOGICAL RECORD IN THE TERRACE LANDSCAPE UNITY, COYLE RIVER MIDDLE BASIN (SANTA CRUZ PROVINCE, ARGENTINA)}

\section{ABSTRACT}

As a result to cultural research management studies on the archaeological record new information is added to the Terraces landscape unit at the Coyle river middle basin (Santa Cruz Province), between the Santa Cruz and Gallegos fluvial basins. The analysis is focused on the spatial distribution of the archaeological record on the surface of geoforms (gullies, closed basins and terraces). Artifactual classes and densities, as well as lithic raw materials, were studied using qualitative and quantitative methods. The evidence indicates that the same types of activities (rock provisioning and flintknapping) were developed along the different geoforms. Nevertheless, artifactual densities show differences related to human intensity use as shown at closed basins. The high frequency of glass scrapers recorded and the results from two new radiocarbon dates place human populations towards the end of the late Holocene. Mollusks from the Atlantic coast and obsidian artifacts suggest the relations with areas located North, East and West. The Terraces landscape unit would have been used in a relatively homogeneous way throughout time, indicating a low human intensity related to residential mobility strategies and to the circulation between the Santa Cruz and Gallegos river basins.

KEY WORDS: Terraces landscape unit, Coyle river middle basin, Late Holocene, hunter gatherers, artefactual distributions, landscape use.

\section{INTRODUCCIÓN}

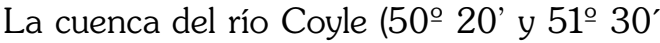
S y $69^{\circ}$ y $72^{\circ}$ O) se ubica en el sur de la provincia de Santa Cruz (Argentina). Limita al norte y al sur con las cuencas de los ríos Santa Cruz y Gallegos, respectivamente. A diferencia de estas últimas, en el Coyle la poca compactación del sedimento Terciario impide la formación de cuevas y aleros que, en especial en el Gallegos, ha incentivado los estudios iniciales. Tanto esta cuenca como la del río Santa Cruz cuentan con una mayor tradición de investigación y con un marco cronológico que ha mostrado el inicio de las ocupaciones humanas desde el Holoceno temprano (entre otros, Borrero 2001).

La información generada en la cuenca proviene de estudios de impacto ambiental sobre el registro arqueológico que cubren de manera paulatina un amplio espacio considerando distintas unidades de paisaje (Belardi et al. 2006; Carballo Marina et al. 2000-2002; Espinosa et al. 2000). El empleo de estas unidades de análisis permite generar información de relevancia regional para la evaluación de la visibilidad, la integridad y resolución de los conjuntos arqueológicos. Además, al tomar en cuenta la litología y el relieve posibilitan ponderar la disponibilidad y la forma en la que se presentan las rocas aptas para la talla de artefactos.
En esta ocasión, se suma nueva evidencia de superficie y a cielo abierto sobre la cuenca media del río Coyle, principalmente en la intercuenca río Coyle - río Santa Cruz, permitiendo así ajustar los conocimientos preexistentes (ver Belardi et al. 2006). El análisis se focaliza sobre la distribución espacial del registro arqueológico en superficie, en especial materiales líticos relevados en la unidad de paisaje Terrazas y en las diferentes geoformas que la componen (terrazas, cañadones y cuencas endorreicas). La información es analizada tanto de manera cualitativa como cuantitativa y es el resultado de una exploración más intensa de la geoforma terrazas respecto de los muestreos implementados entre los años 2000 y 2006 (Fig. 1). A la vez, se amplía el marco cronológico regional.

En primer lugar se presenta el marco ambiental de la unidad de paisaje Terrazas, enfatizando las geoformas trabajadas. Luego se mencionan los antecedentes regionales que enmarcan la nueva información y, con respecto a ella, se discute por geoforma la densidad artefactual, las materias primas utilizadas y la representación de tipos artefactuales. Por último, se brindan las nuevas dataciones radiocarbónicas.

Los resultados se evalúan en el marco regional reforzando las tendencias ya observadas en cuanto al uso de la unidad de paisaje Terrazas y la crono- 


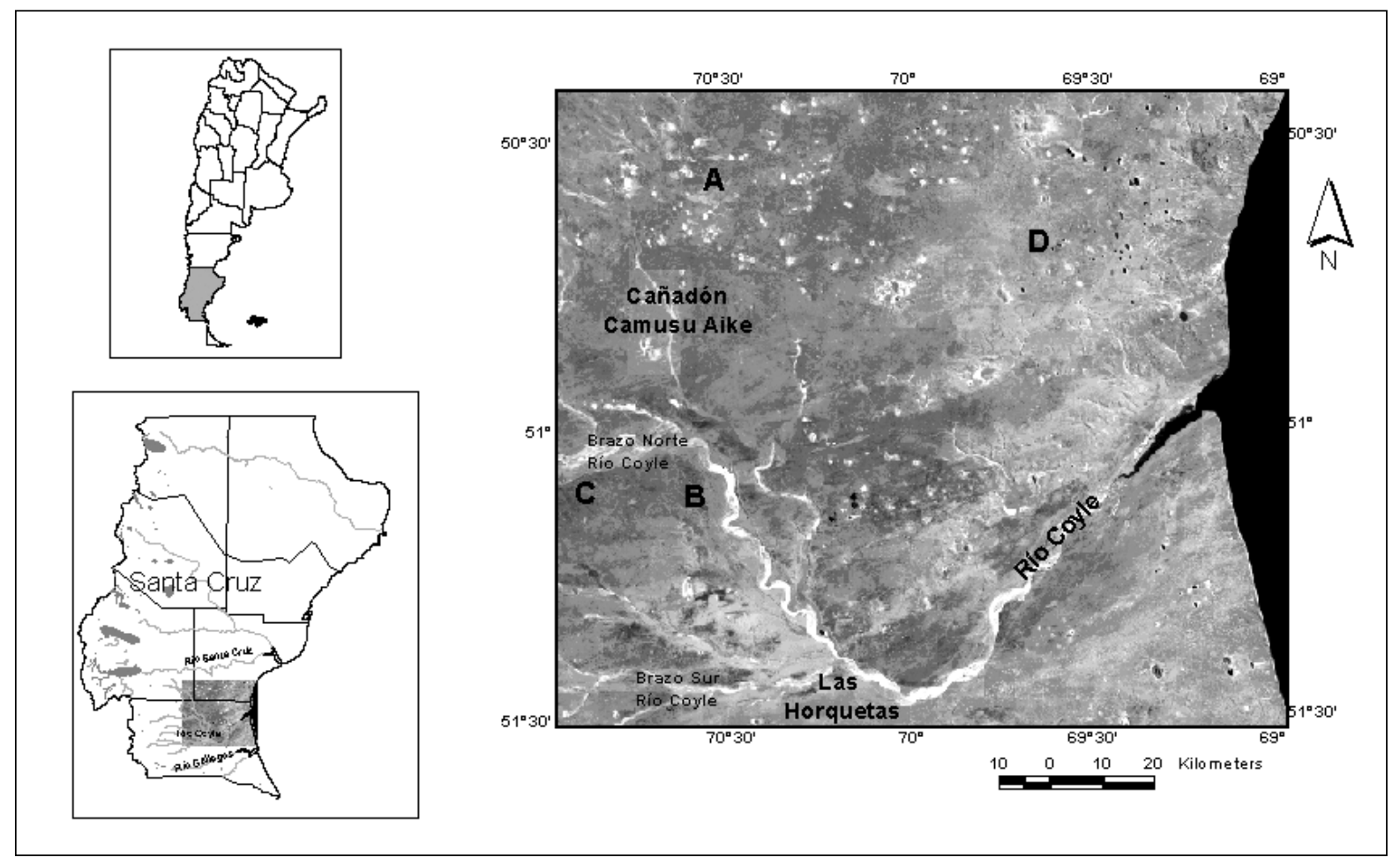

Fig. 1. Mapa de la región de estudio. Las letras (A, B, C y D) se corresponden con la ubicación aproximada de localidades enumeradas en la Tabla 1.

logía de las ocupaciones cazadoras recolectoras en la cuenca media del río Coyle. En este sentido, no parecen haber existido variaciones significativas en la forma de uso de dicha unidad de paisaje a lo largo del tiempo, indicando una baja intensidad vinculada con estrategias eminentemente residenciales (sensu Binford 1980). Dichas características sugieren diferencias con respecto a la forma de uso de las cuencas de los ríos Santa Cruz y Gallegos y con la costa atlántica.

\section{EL AMBIENTE REGIONAL}

La cuenca del río Coyle se conforma por dos grandes brazos. El Brazo Norte nace en la meseta de Las Vizcachas, mientras que el Brazo Sur lo hace en la meseta Latorre; confluyen en la localidad de Las Horquetas y desembocan en el océano Atlántico en forma de estuario. Presenta pocos afluentes de magnitud, entre los que se cuenta el río Pelque y los cañadones Camusu-Aike, Deus, Magán y Corpie Aike (Cáceres y Caballero 2006). En términos operativos la cuenca media se define como aquel espacio comprendido al oeste entre las localidades La Esperanza y Las Horquetas y hacia el este hasta la Ruta Nacional № 3 (Fig. 1).

La mayor superficie de la cuenca corresponde al área ecológica "Matorral de Mata Negra" caracterizada por una estepa arbustiva de porte mediano (Cuadra y Oliva 1996). Un sector de la porción sur de la misma pertenece al área ecológica "Estepa Magallánica" (Oliva et al. 2001). La estepa arbustiva tiene una regular visibilidad arqueológica, lo que determinó que la información se obtuviera en aquellos lugares con porcentajes de cobertura vegetal $\leq 50 \%$ (Belardi et al. 2006).

El río Coyle conforma un complejo sistema de terrazas con un mínimo de cuatro niveles, denominados T II a V desde el más antiguo, ubicado en la posición topográfica más elevada, al más joven -las T IV y T V corresponden ya al fondo del valle. A partir de esto se proponen dos unidades de paisaje: Terrazas y Fondo de valles.

La unidad de paisaje Terrazas está constituida por sedimentos continentales finos y friables, como areniscas, arcilitas y tobas del Mioceno (Formación 
Santa Cruz) cubiertos por un manto de "Rodados Patagónicos" (Fidalgo y Riggi 1970), de pocos metros de espesor, los que posiblemente correspondan a depósitos glacifluviales antiguos (Plioceno a Pleistoceno temprano). Como fuera mencionado, no hay posibilidades de génesis de abrigos rocosos -cuevas y aleros- por la poca compactación de los sedimentos del Terciario.

La superficie geomórfica más elevada de la región corresponde a la Terraza Antigua (T A), a partir de la cual los sistemas fluviales iniciaron su profundización. El desnivel que existe entre $\mathrm{T}$ A y la terraza superior (T II), es de unos $30 \mathrm{~m}$. Entre los otros niveles los resaltos son inferiores. Las pendientes son moderadas a fuertes, están estabilizadas y cubiertas por depósitos coluviales de algunos metros de espesor (Carballo Marina et al. 2000-2002). La T A es una extensa planicie disectada por cañadones y cuencas endorreicas o "bajos sin salida" ubicada entre las cotas de 190 y 230 m. Los cañadones forman un sistema de valles secundarios de pocos kilómetros de extensión y desniveles poco pronunciados (se destacan Camusu Aike y Deus). En ellos, y a diferencia de las terrazas, la conjunción de la alta sedimentación, del sustrato húmedo y la mayor cobertura vegetal determinan mayores probabilidades de conservación de restos arqueológicos por enterramiento.

El nivel T II es el más amplio y el único que aparece en forma continua en ambas márgenes del río. Se localiza a unos $35 \mathrm{~m}$ de altura sobre el nivel del cauce actual. El relieve suavemente ondulado de la superficie de los niveles T II y T III es producto de la acción fluvial que originó una red de drenaje conformada por numerosos cañadones y cárcavas actualmente afuncionales (Carballo Marina et al. 2000-2002).

En los distintos niveles de terraza existen cuencas endorreicas de diferentes tamaños, de probable origen hidroeólico. Disponen de agua temporalmente -su desarrollo se regula por el balance precipitación-evaporación anual- y tienen una distribución prácticamente continua (Diéguez 2003). La mayor frecuencia de cuencas endorreicas se presenta en el interfluvio Coyle-Santa Cruz. Todos muestran una reducción en su superficie, lo que evidencia las condiciones de desecación imperantes en la actualidad. En función de su posición geográfica algunos están sujetos a procesos de congelamiento en época invernal (Mazzoni et al. 1999). A la vez, son lugares que brindan reparo de los vientos predominantes y concentran recursos. Por ejemplo, su valor biológico se basa sobre la diversidad de aves acuáticas que albergan, las que incluyen tanto especies residentes como migratorias. La mayor variedad se observa en primavera-verano, cuando convergen especies provenientes del hemisferio norte y del centro-norte del país (Mazzoni et al. 1999). También actúan como canteras potenciales, debido a que exponen rodados patagónicos de variada litología y tamaños aptos para la talla. No sólo se destaca su abundancia sino que, dada su relación con las cuencas endorreicas, su distribución es relativamente homogénea. Este modo de presentación de las materias primas en el espacio regional también ocurre en los cauces desactivados y en las laderas de los cañadones (Espinosa et al. 2000).

La otra unidad de paisaje, Fondo de valles, corresponde a los niveles de terraza más recientes (TIV y TV) caracterizada por un relieve ondulado, constituida por sedimentos finos y en menor medida por gravas. Se destaca que la cuenca del río Coyle presenta la mayor superficie de mallines humedales de toda la provincia de Santa Cruz, 98.000 ha. (Mazzoni y Vázquez 2001). El río ha profundizado alrededor de $1 \mathrm{~m}$ los sedimentos de T V desarrollando una planicie de inundación muy estrecha.

Cabe señalar que Fondo de Valles y las terrazas T II y T III han sido definidas como de bajo riesgo climático invernal mientras que en la $\mathrm{T}$ A el riesgo es medio. Esta caracterización es compartida con las cuencas medias de los ríos Santa Cruz y Gallegos (Borrelli et al. 1997).

Los antecedentes paleoambientales más cercanos de la región de estudio provienen de la laguna Potrok Aike, ubicada en el campo volcánico Pali Aike (Haberzettl et al. 2005), y de la laguna Las Vizcachas, localizada en la meseta homónima (Fey et al. 2009), al sur y al oeste respectivamente. La información comparada para los últimos 1600 años AP sugiere un patrón inverso de precipitaciones y temperaturas; con mayor humedad y más frío hacia el oeste (Fey et al. 2009). Sobre esta base, la región bajo análisis se vincularía con el patrón observado en Potrok Aike ya que ambas se ubican sobre la misma franja longitudinal. Por lo expuesto, podría esperarse que las condiciones hayan sido más secas y menos frías, hecho que habría repercutido en la disponibilidad de agua temporal en las cuencas 
endorreicas y por ende en la movilidad cazadora recolectora por el curso medio del río Coyle.

\section{ANTECEDENTES DE INVESTIGACIÓN}

El valle del río Coyle ha sido caracterizado como una de las grandes vías potenciales de circulación de poblaciones entre la vertiente atlántica y la cordillera (Carballo Marina et al. 2000-2002).

Los primeros trabajos en la cuenca media se efectuaron sobre la base de su segmentación en Terrazas y Fondos de valles, con el propósito de reconocer el paisaje arqueológico característico. La ubicación temporal del registro arqueológico corresponde al final del Holoceno tardío (Carballo Marina et al. 2000-2002). La densidad artefactual $\left(\mathrm{m}^{2}\right)$ regional es muy baja, con un orden de magnitud de $10^{-4}$, apoyando un uso humano poco intenso del espacio. Las frecuencias mayores se vinculan tanto con eventos de talla y aprovisionamiento en canteras, como con la existencia de cuencas endorreicas y sectores de cañadones (Espinosa et al. 2000). Otra característica del paisaje arqueológico es la preeminencia en el uso de rocas locales para la manufactura de artefactos, entre los que predominan los desechos de talla, núcleos y raederas. También evidencia un importante componente expeditivo vinculado con la distribución homogénea y la alta disponibilidad de rocas.

Las materias primas más frecuentes son las dacitas, las Rocas de Grano Fino Oscuras (RGFO) -sensu Charlin 2005-, denominadas basaltos en trabajos anteriores) y la andesita, seguidas por las rocas silíceas. En todos los casos son mayoría las rocas de calidades buenas y muy buenas para la talla (sensu Aragón y Franco 1997). La alta frecuencia de lascas corticales y núcleos señala la importancia de la realización de tareas de desbaste inicial de rocas con alta disponibilidad local. Por otra parte, en un tributario del Cañadón Camusu Aike llamado cañadón del Baile se hallaron raspadores de vidrio asociados a botellas y frascos de diferentes formatos y colores. Estos artefactos fueron asignados a la primera mitad del siglo XX y se asociarían con la ocupación de la reserva Tehuelche Camusu Aike (Carballo Marina et al. 2000-2002).

La presencia de obsidiana negra y gris verdosa veteada -en bajas frecuencias-, junto con un ejemplar de Panopea abbreviata, molusco cuya distribución actual abarca desde Río de Janeiro (Brasil) hasta la localidad de Puerto Deseado (provincia de Santa Cruz), podría ser ligada con redes de intercambio/ circulación de bienes/información con poblaciones localizadas principalmente al norte, al oeste y al este de la región (Belardi et al. 2006; Carballo Marina et al. 2000-2002). Estas particularidades, asemejan a la cuenca media del río Coyle con la cuenca superior del río Santa Cruz y a la de los ríos Gallegos y Chico (Carballo Marina et al. 2000-2002; Espinosa et al. 2000).

\section{METODOLOGÍA}

Los muestreos se llevan a cabo en las distintas geoformas de la unidad de paisaje Terrazas. La elección de las localidades muestreadas responde exclusivamente a las solicitudes de relevamientos de campo que requerían las empresas contratistas.

Con el propósito de favorecer la comparación de los resultados se continúa con la perspectiva de análisis distribucional (entre otros, Foley 1981) y recuperación del registro arqueológico aplicada en trabajos anteriores. Se emplean transectas continuas y discontinuas. Además, en casos puntuales, se aplican unidades de recolección de diferentes dimensiones. Se evalúan las condiciones de visibilidad, estimada sobre el porcentaje de cobertura vegetal existente en las unidades de muestreo. Resultan así cuatro categorías: muy buena (0-25 \%), buena (26-50 \%), regular (51-75 \%) y mala (76-100 \%).

Las materias primas líticas se determinan macroscópicamente. Se emplea la categoría RGFO para incluir a las rocas que fueron categorizadas previamente como basalto, mientras que bajo el rótulo de rocas silicificadas se engloba principalmente a sílices coloreados, ópalos y calcedonias. Uno de los espacios relevados presenta una alta frecuencia de artefactos de vidrio de botella y frascos ( $\mathrm{N}=1038)$. La calidad de las materias primas líticas aptas para la talla: fueron calificadas como excelente, muy buena, buena y regular (Aragón y Franco (1997).

Con respecto a los artefactos se consideran las diferentes clases (Aschero 1975, rev. 1983). En los cómputos sólo se contemplan aquellos artefactos que presentan talón, los núcleos y los artefactos formatizados.

Por medio del software estadístico Info Stat 2010 se tratan las variables densidad artefactual por $\mathrm{m}^{2}$, jerarquización artefactual sobre la base de las 
Tabla 1. Localidades muestreadas en la unidad de paisaje Terrazas.

\begin{tabular}{|c|c|c|c|}
\hline $\begin{array}{c}\text { Localidad } \\
\text { (Ver en el Fig. } 1 \text { A-B-C-D) }\end{array}$ & Superficie muestreada $\mathbf{m}^{2}$ & $\mathbf{N}$ artefactual & $\begin{array}{c}\text { Densidad } \\
\mathrm{m}^{2} \cdot 10^{-4}\end{array}$ \\
\hline \multicolumn{4}{|c|}{ Terrazas } \\
\hline Y. Agua Fresca -A- & 62.750 & 53 & 8,4 \\
\hline Y. Agua Fresca- Y. Puesto Peter -A- & 330.000 & 152 & 4,6 \\
\hline Y. Campo Indio -A- & 193.300 & 38 & 1,9 \\
\hline Y. Cañadón Salto -A- & 47.000 & 0 & 0 \\
\hline Y. Dos Hermanos -A- & 21.000 & 1 & 0,4 \\
\hline Y. Cañadón Deus -A- & 28.000 & 0 & 0 \\
\hline Y. Barda Las Vegas -B- & 23.000 & 1 & 0,4 \\
\hline Y. María Inés -B- & 27.100 & 26 & 9,5 \\
\hline Y. El Chiripá -C- & 16.000 & 0 & 0 \\
\hline Y. El Campamento -A- & 30.500 & 7 & 2,2 \\
\hline Y. La Paz -A- & 78.500 & 6 & 0,7 \\
\hline Y. El Cerrito -A- & 28.000 & 1 & 0,3 \\
\hline Y. La Maggie -D- & 8.000 & 2 & 2,5 \\
\hline Y. Los Capones -D- & 17.000 & 0 & 0 \\
\hline TOTALES & 801.150 & 287 & \\
\hline \multicolumn{4}{|c|}{ Cañadones } \\
\hline Y. El Chiripá. Cañadón 1 -C- & 1.500 & 4 & 26,6 \\
\hline Y. El Chiripá. Cañadón 2 -C- & 2.000 & 24 & 120 \\
\hline Y. El Chiripá. Cañadón 3 -C- & 1.000 & 8 & 80 \\
\hline Y. El Chiripá. Cañadón 4 -C- & 500 & 49 & 980 \\
\hline Y. El Chiripá. Cañadón 5 -C- & 1.000 & 0 & 0 \\
\hline Y. La Paz. (Eas. La Realidad - La Nueva) -A- & 5.000 & 13 & 26 \\
\hline Y La Maggie. Cañadón El Falso -D- & 504 & 30 & 595,2 \\
\hline TOTALES & 11.504 & 128 & \\
\hline \multicolumn{4}{|c|}{ Cuencas endorreicas } \\
\hline Y. Campo Indio. CI A1002 -A- & 24 & 1040 & 43.432 \\
\hline Y. Dos Hermanos. Laguna Dos Hermanos -A- & 600 & 187 & 3.116 \\
\hline Y. El Chiripá (Cuenca endorreica) -C- & 16 & 43 & 26,8 \\
\hline Y. El Chiripá. Bajo 1 -C- & 8.000 & 31 & 38,7 \\
\hline Y. El Chiripá. Bajo 2 -C- & 4.750 & 98 & 206,3 \\
\hline Y. La Maggie. Bajo Ea. La Argentina -C- & 1.500 & 53 & 353 \\
\hline Y. La Maggie. Bajo El Barril -D- & 500 & 10 & 200 \\
\hline Y. La Maggie. Bajo El Mate -D- & 560 & 62 & 107,41 \\
\hline Y. La Maggie. Bajo Del Medio -D- & 400 & 16 & 375 \\
\hline Y. La Maggie. (Ea. Domi Aike) -D- & 1.000 & 15 & 150 \\
\hline Y. Los Capones. (Ea. Los Luises) -D- & 7.000 & 133 & 190 \\
\hline Y. Los Capones Bajo 1 -D- & 15.000 & 123 & 82 \\
\hline Y. Los Capones Bajo 2 -D- & 13.000 & 10 & 7,6 \\
\hline Y. Los Capones Bajo 3 (Ea. La Araceli) -D- & 18.900 & 98 & 51,8 \\
\hline Y. Los Capones Bajo 4 (Ea. La Concordia) -D- & 10.000 & 47 & 47 \\
\hline Y. Los Capones Bajo 5 -D- & 12.000 & 38 & 33,3 \\
\hline Y. Los Capones Bajo 6 -D- & 7.000 & 124 & 177,1 \\
\hline Y. Los Capones Bajo 7 -D- & 24.000 & 149 & 62 \\
\hline Y. Los Capones Bajo 8 (Ea. Ototel Aike) -D- & 10.500 & 16 & 15,24 \\
\hline Y. Los Capones Bajo 9 (Ea. Los Álamos) -D- & 24.500 & 29 & 11,83 \\
\hline TOTALES & 152.250 & 2322 & \\
\hline
\end{tabular}


frecuencias y las tres materias primas de frecuencias más altas en cada una de las geoformas. Sólo se tienen en cuenta aquellas localidades donde se produjeron hallazgos (ver Tabla 1).

El análisis estadístico comienza en su etapa exploratoria y descriptiva considerando las medidas clásicas de posición y variabilidad tanto para la densidad artefactual como para la jerarquización en cada categoría (Tabla 2). Además, se procede a probar la normalidad u otra posible distribución estadística de los datos. Ante la carencia de ajuste a una distribución usual, se calculan las correlaciones cruzadas entre cada par de variables (densidad artefactual, materias primas líticas y riqueza artefactual) en cada geoforma. Para establecer si el comportamiento de las variables es estadísticamente similar o si se aprecian diferencias significativas se opta por continuar con un análisis de Anova no paramétrico. Mientras que para evaluar la homogeneidad interna de las muestras respecto de las materias primas y las clases artefactuales se aplica el test de Kruskal - Wallis. También mediante el coeficiente de Spearman se procede al análisis de correlación no paramétrico entre las variables.

La información se presenta en distintas tablas detallando las localidades y las geoformas (terraza, cañadón y cuencas endorreicas) muestreadas. Las localidades se enumeran de norte a sur y de este a oeste. En cada caso se explicita la superficie relevada, las frecuencias y densidades artefactuales, las frecuencias y porcentajes de las materias primas líticas empleadas y las clases artefactuales.

\section{RESULTADOS}

\section{Densidades artefactuales}

En la Tabla 1 y en la Fig. 1 se presentan los espacios y superficies relevadas y la frecuencia y densidad artefactual para cada uno de ellos. Con respecto a esta última variable se expresa en el orden de magnitud $10^{-4}$.

La superficie total muestreada es de 964.904 $\mathrm{m}^{2}$ y la visibilidad arqueológica fue estimada entre buena y muy buena. En las terrazas los relevamientos cubren el 83\% de la superficie. Se recuperó un total de 287 artefactos líticos. La superficie prospectada en cañadones equivale al $2 \%$ y se obtuvieron 128 , mientras que, en las cuencas endorreicas el porcentaje trepa al 16\% y se registraron 2322 artefactos. Si se considera que en estas últimas dos geoformas las posibilidades de enterramiento son mayores, se puede postular que la densidad artefactual sea aún más elevada.

En primer lugar se estudia la variabilidad de los datos de la densidad artefactual con el propósito de evaluar los parámetros de forma y dispersión en cada geoforma (Tabla 2). De los valores de los parámetros de tendencia y dispersión se desprende que -en general- existe un alto grado de variabilidad interna en los mismos. Este fenómeno se refleja en los altos niveles porcentuales de los coeficientes de variación (CV terrazas: 133,32 \%; cañadones: 144,95 $\%$ y cuencas endorreicas 414,66 \%). Además, los datos no superan el test de normalidad de Shapiro Wilks modificado en 1997. De las distribuciones más usuales que se presentan en estos casos, sólo puede considerarse -como muy poco probable- un ajuste poco significativo a la distribución $t$ de Student, con un $\mathrm{p}$-valor menor que 0,002 , según se desprende del test de bondad de ajuste de Kolmogorov.

En cañadones, si bien la frecuencia absoluta de datos es menor que en las otras dos geoformas, no se observa la presencia de outliers y exhibe el p-valor que más se acerca a la normalidad según el test de Shapiro-Wilks. No obstante ello, tampoco se ajusta significativamente a esa distribución por los valores que presenta de sesgo y kurtosis. Debido

Tabla 2. Variables descriptivas para la densidad artefactual en cada geoforma.

\begin{tabular}{|l|c|c|c|}
\hline \multicolumn{1}{|c|}{ Variables } & Terrazas & Cañadones & Cuencas endorreicas \\
\hline N conjuntos & 14 & 7 & 20 \\
\hline Coeficiente de variación & 133,32 & 144,95 & 414,66 \\
\hline $\begin{array}{l}\text { Shapiro-Wilks (modificado) } \\
\text { P (Unilateral D) }\end{array}$ & $<0,0001$ & 0,0088 & $<0,0001$ \\
\hline $\begin{array}{l}\text { Kolmogorov Normal } \\
\text { T Student (14) } \\
\text { p-valor }\end{array}$ & 0,0018 & 0,3256 & 0,0002 \\
\hline
\end{tabular}


Tabla 3. Localidades muestreadas en la geoforma Terrazas discriminadas por materias primas. Referencias: RGFO: Rocas de Grano Fino Oscuras, Dac: Dacita, Dia: Diabasa; An: Andesita, R Sil.: Rocas silíceas, M.Sil: Madera silicificada, Obs: Obsidiana

\begin{tabular}{|c|c|c|c|c|c|c|c|}
\hline \multicolumn{8}{|c|}{ Terrazas } \\
\hline Localidad & RGFO & Dac & Dia & An & R. Sil & M.Sil & Obs \\
\hline Y. Agua Fresca & 40 & 8 & 4 & 0 & 0 & 1 & 0 \\
\hline Y. Agua Fresca- Y. Puesto Peter & 62 & 23 & 60 & 0 & 4 & 1 & 2 \\
\hline Y. Campo Indio & 17 & 17 & 4 & 0 & 0 & 0 & 0 \\
\hline Y. Dos Hermanos & 1 & 0 & 0 & 0 & 0 & 0 & 0 \\
\hline Y. Barda Las Vegas & 1 & 0 & 0 & 0 & 0 & 0 & 0 \\
\hline Y. María Inés & 15 & 6 & 0 & 5 & 0 & 0 & 0 \\
\hline Y. El Campamento & 3 & 1 & 3 & 0 & 0 & 0 & 0 \\
\hline Y. La Paz & 4 & 2 & 0 & 0 & 0 & 0 & 0 \\
\hline Y. El Cerrito & 0 & 0 & 0 & 1 & 0 & 0 & 0 \\
\hline Y. La Maggie & 0 & 1 & 0 & 0 & 1 & 0 & 0 \\
\hline $\begin{array}{l}\text { TOTAL y } \\
\%\end{array}$ & $\begin{array}{c}143 \\
49,8\end{array}$ & $\begin{array}{c}58 \\
20,2\end{array}$ & $\begin{array}{c}71 \\
24,7\end{array}$ & $\begin{array}{c}6 \\
2,09\end{array}$ & $\begin{array}{c}5 \\
1,7\end{array}$ & $\begin{array}{c}2 \\
0,6\end{array}$ & $\begin{array}{c}2 \\
0,6\end{array}$ \\
\hline
\end{tabular}

al tamaño reducido de la muestra no se consideró proceder al recorte de datos.

Por otra parte, en la unidad de paisaje Terrazas no se observa un alto grado de correlación lineal entre la superficie muestreada y la frecuencia artefactual (r Spearman -0,22; p-valor 0,17), lo que se relacionaría con el alto $\mathrm{CV}$ de las geoformas.

Se destaca que la densidad artefactual regional es muy baja (con el orden de magnitud $10^{-4}$ ), apoyando los resultados de las investigaciones previas. Las cuencas endorreicas concentran las mayores frecuencias y más altas densidades de materiales arqueológicos, hecho que se vincularía con la disponibilidad de reparo, principalmente en sus márgenes oeste y norte y los recursos que concentran. Tal es el caso del Yacimiento Campo Indio donde se localizó el sitio CI A 1002 con una elevada frecuencia de artefactos de vidrio (Tablas 1 y 6). Este sitio, al igual que el cañadón del Baile, también se encuentra en el predio de la reserva Tehuelche Camusu Aike.

\section{Materias primas líticas}

Entre las rocas empleadas predominan las RGFO, dacita y diabasa; todas ellas disponibles localmente y de buena y muy buena calidad para la talla (Tablas 3, 4 y 5). Las RGFO son mayoritarias en terrazas y cañadones, aunque en éstos últimos la diferencia es mínima. En cuencas endorreicas esta relación se invierte, más aún cuando no se considera al vidrio, de excelente calidad para la talla.

Para analizar diferencias estadísticas en la representación de materias primas líticas se utiliza la prueba de Kruskal-Wallis considerando para ello las tres rocas de mayor representación porcentual. La aplicación de esta prueba permite afirmar que hay homogeneidad en el comportamiento de las variables (geoformas y materias primas) (KruskalWallis y t Test) por lo cual se mantiene la hipótesis nula, es decir que no se observan diferencias estadísticamente significativas en la representación

Tabla 4. Localidades muestreadas en la geoforma Cañadones discriminadas por materias primas. Referencias: RGFO: Rocas de Grano Fino Oscuras, Dac: Dacita, Dia: Diabasa, R Sil.: Rocas silíceas, M. Sil: Madera silicificada. + evento de talla en dacita muy buena, un núcleo, dos externas y 4 internas; * ópalo.

\begin{tabular}{|l|c|c|c|c|c|}
\hline \multicolumn{1}{|c|}{ Localidad } & RGFO & Dac & Dia & R. Sil & M. Sil \\
\hline Y. El Chiripá. Cañadón 1 & 2 & 1 & 1 & 0 & 0 \\
\hline Y. El Chiripá. Cañadón 2 & 18 & 5 & 0 & 1 & 1 \\
\hline Y. El Chiripá. Cañadón 3 & 6 & 0 & 0 & 1 & 1 \\
\hline Y. El Chiripá. Cañadón 4 & 9 & 17 & 1 & $21^{*}$ & 1 \\
\hline Y. La Paz. (Eas. La Realidad - La Nueva) & 0 & $10+$ & 3 & 0 & 0 \\
\hline Y. La Maggie. Cañadón El Falso & 14 & 14 & 2 & 0 & 0 \\
\hline TOTAL y & $\mathbf{4 9}$ & $\mathbf{4 7}$ & $\mathbf{7}$ & $\mathbf{2 3}$ & $\mathbf{2}$ \\
$\mathbf{\%}$ & $\mathbf{3 8 , 2}$ & $\mathbf{3 6 , 7}$ & $\mathbf{5 , 4}$ & $\mathbf{1 7 , 9}$ & $\mathbf{1 , 5}$ \\
\hline
\end{tabular}


Tabla 5. Localidades muestreadas en la geoforma Cuencas endorreicas discriminadas por frecuencia de materias primas. Referencias: RGFO: Rocas de Grano Fino Oscuras, Dac: Dacita, Dia: Diabasa; An:

Andesita, R Sil.: Rocas silíceas, M. Sil: Madera silicificada, Gr: Granito, Obs: Obsidiana, Vd. Vidrio.

\begin{tabular}{|l|c|c|c|c|c|c|c|c|c|}
\hline \multicolumn{1}{|c|}{ Localidad } & RGFO & Dac & Dia & An & R. Sil & M.Sil & Gr & Obs & Vd \\
\hline & 0 & 2 & 0 & 0 & 0 & 0 & 0 & 0 & 1038 \\
\hline Y. Campo Indio. CI A1002 & 36 & 125 & 0 & 2 & 17 & 5 & 0 & 2 & 0 \\
\hline $\begin{array}{l}\text { Y. Dos Hermanos. } \\
\text { Laguna Dos Hermanos }\end{array}$ & 31 & 2 & 0 & 0 & 6 & 4 & 0 & 0 & 0 \\
\hline Y. El Chiripá. (Cuenca endorreica) & 22 & 8 & 0 & 0 & 1 & 0 & 0 & 0 & 0 \\
\hline Y. El Chiripá. Bajo 1 & 42 & 23 & 12 & 0 & 9 & 11 & 1 & 0 & 0 \\
\hline Y. El Chiripá. Bajo 2 & 6 & 47 & 0 & 0 & 0 & 0 & 0 & 0 & 0 \\
\hline Y. La Maggie. Bajo Ea. La Argentina & 0 & 9 & 1 & 0 & 0 & 0 & 0 & 0 & 0 \\
\hline Y. La Maggie. Bajo El Barril & 25 & 35 & 0 & 0 & 0 & 0 & 1 & 1 & 0 \\
\hline Y. La Maggie. Bajo El Mate & 1 & 10 & 5 & 0 & 0 & 0 & 0 & 0 & 0 \\
\hline Y. La Maggie. Bajo Del Medio & 6 & 9 & 0 & 0 & 0 & 0 & 0 & 0 & 0 \\
\hline Y. La Maggie. (Ea. Domi Aike) & 37 & 79 & 14 & 0 & 0 & 0 & 2 & 1 & 0 \\
\hline Y. Los Capones. (Ea. Los Luises) & 48 & 56 & 2 & 0 & 7 & 2 & 2 & 6 & 0 \\
\hline Y. Los Capones. Bajo 1 & 1 & 9 & 0 & 0 & 0 & 0 & 0 & 0 & 0 \\
\hline Y. Los Capones. Bajo 2 & 16 & 70 & 2 & 0 & 1 & 2 & 7 & 0 & 0 \\
\hline Y. Los Capones. Bajo 3 (Ea. La Araceli) & 11 & 30 & 5 & 0 & 0 & 1 & 0 & 0 & 0 \\
\hline Y. Los Capones. Bajo 4 (Ea. La Concordia) & 10 & 28 & 0 & 0 & 0 & 0 & 0 & 0 & 0 \\
\hline Y. Los Capones. Bajo 5 & 39 & 69 & 2 & 0 & 5 & 7 & 2 & 0 & 0 \\
\hline Y. Los Capones. Bajo 6 & 73 & 74 & 0 & 1 & 1 & 0 & 0 & 0 & 0 \\
\hline Y. Los Capones. Bajo 7 & 4 & 9 & 3 & 0 & 0 & 0 & 0 & 0 & 0 \\
\hline Y. Los Capones. Bajo 8 (Ea. Ototel Aike) & 11 & 15 & 2 & 0 & 1 & 0 & 0 & 0 & 0 \\
\hline Y. Los Capones. Bajo 9 (Ea. Los Alamos) & $\mathbf{4 1 9}$ & $\mathbf{7 0 9}$ & $\mathbf{4 8}$ & $\mathbf{3}$ & $\mathbf{4 8}$ & $\mathbf{3 2}$ & $\mathbf{1 5}$ & $\mathbf{1 0}$ & $\mathbf{1 0 3 8}$ \\
\hline TOTAL y \\
\% (con vidrio) & $\mathbf{1 8 , 0 4}$ & $\mathbf{3 0 , 5}$ & $\mathbf{2 , 0 6}$ & $\mathbf{0 , 1}$ & $\mathbf{2 , 0 6}$ & $\mathbf{1 1 , 3}$ & $\mathbf{0 , 6}$ & $\mathbf{0 , 4}$ & $\mathbf{4 4 , 7}$ \\
\hline \% (sin vidrio) & $\mathbf{3 2 , 6}$ & $\mathbf{5 5 , 2}$ & $\mathbf{3 , 7}$ & $\mathbf{0 , 2}$ & $\mathbf{3 , 7}$ & $\mathbf{2 , 4}$ & $\mathbf{1 , 1}$ & $\mathbf{0 , 7}$ & \\
\hline
\end{tabular}

de las materias primas líticas de acuerdo con cada una de las geoformas. Esto sucede tanto cuando se incluye o no en el análisis al vidrio. Por otra parte, en la unidad de paisaje Terrazas se observa una alta correlación lineal entre la frecuencia artefactual y las materias primas representadas ( $\mathrm{r}$ de Spearman 0,80 y p-valor menor que $4,7 \cdot 10^{-7}$ ).

En los cañadones la presencia de rocas silicificadas es alta, hecho que se explicaría por el hallazgo en Yacimiento El Chiripá, Cañadón 4 de un evento de talla en ópalo (Tabla 4). Por su parte, la obsidiana se da en bajísimas y similares proporciones en terrazas y cuencas endorreicas, indicando una circulación esporádica en la cuenca media del río Coyle. Se han registrado las variedades gris verdosa veteada y negra, tal el caso del Yacimiento Los Capones. Bajo 1 (ver Tabla 5). La primera proveniente de las mesetas basálticas del sur de la cuenca superior del río Santa Cruz -cordillera de Los Baguales- (Stern y Franco 2000) y la segunda de la Pampa del Asador localizada a $400 \mathrm{~km}$ al noroeste de la cuenca media del Coyle (Belardi et al. 2006; Espinosa y Goñi 1999, Stern 1999).

Por último y, como ya se mencionara, se destaca la presencia de vidrio en el Yacimiento Campo Indio en el sitio CI A 1002 (Tabla 5).

\section{Clases artefactuales}

En todas las geoformas predominan los desechos de talla, con una proporción importante de desechos externos. Le siguen los núcleos, las raederas y raspadores (Tablas 6, 7, y 8). Estas clases se utilizan para la prueba de Kruskal-Wallis y t Test con el fin de evaluar diferencias estadísticas en su representación por geoforma. Al igual que lo sucedido con las materias primas, se mantiene la hipótesis nula. Así, en la unidad de paisaje no se observan diferencias estadísticamente significativas en cuanto a la representación de dichas clases artefactuales por 
geoforma. Esto sucede independientemente que sean o no considerados los raspadores manufacturados en vidrio. Entonces, en toda la unidad de paisaje se estarían realizando el mismo tipo de actividades. Por otra parte, hay una correlación positiva y alta entre la frecuencia de artefactos y la riqueza ( $r$ Spearman 0,80 p-valor menor que 4,7.10-7).

La preponderancia de desechos de talla y núcleos se debería al aprovechamiento inmediato de rocas disponibles localmente. La principal actividad llevada a cabo se relacionaría con los primeros estadios de reducción de núcleos y manufactura de artefactos. El alto porcentaje de núcleos no agotados (> 50\%) y de artefactos formatizados abandonados (> 50\%) se orienta en dicho sentido. Esto sugiere la preeminencia de estrategias tecnológicas expeditivas (Nelson 1991) en el manejo de los recursos líticos. En el caso de las terrazas se registraron eventos de talla, tal como lo demuestra la observación de conjuntos de núcleos y desechos de una misma materia prima en superficies reducidas (1-2 $\mathrm{m}^{2}$ ) (Carballo Marina et al. 2000-2002). Lo mismo sucede en cañadones, donde se relevó un ejemplo aprovechando dacita -Y. La Paz. Eas. La Realidad - La Nueva- y ópalo -Y. El Chiripá 4 (ver Tabla 7). A ello se suma lo observado en locaciones ubicadas sobre el borde oeste de la barda del río Coyle, en las que la frecuencia artefactual es alta (Y. María Inés, Tabla 6). Esta situación acuerda con el resultado de relevamientos previos llevados a cabo en la cuenca media del río y se relacionaría no sólo con la buena disponibilidad de rocas aptas para la talla, sino también con su ubicación topográfica que permite una muy buena visibilidad del entorno (Belardi et al. 2006).

Las cuencas endorreicas y los cañadones no sólo muestran la mayor diversidad de artefactos sino también la mayor proporción de tipos artefactuales mayoritarios (raederas y raspadores seguidos por las puntas de proyectil, FAF, AFS y bifaces, aunque en una frecuencia mucho menor). Las puntas de proyectil han sido manufacturadas en RGFO, son atribuibles a la denominada Magallanes IV (Bird 1988) y, en general, a diferencia del resto de los artefactos formatizados, se encuentran reactivadas (Fig. 2). Si bien con muy baja frecuencia también se destaca la presencia de perforadores en las cuencas endorreicas del Y. Los Capones (Ea. Los Luises) y de cepillos en el Y. Dos Hermanos. Laguna Dos Hermanos (Tabla 8). A la vez, en la Ea. Los Luises se halló un ejemplar de Nacella magellanica y otro de Mytilus edulis, moluscos de procedencia atlántica, costa distante a unos $35 \mathrm{~km}$.

En el Y. Campo Indio, en el sitio CI A 1002, se destaca la presencia de una frecuencia muy alta de raspadores ( $\mathrm{N}=73$ ) (Fig. 3), fragmentos de artefactos formatizados $(\mathrm{N}=89)$ y desechos de su manufactura en vidrio de botella y frascos de diferentes colores.

Las diferencias señaladas en cuanto a la mayor frecuencia relativa de los artefactos formatizados, la presencia de núcleos y la mayor densidad artefactual en cuencas endorreicas y cañadones se explican en

Tabla 6. Localidades muestreadas en la geoforma Terrazas discriminadas por frecuencia de clases artefactuales. Referencias: DE: Desecho externo, DI: Desecho interno, N: Núcleo; Ra: Raedera, Rp: Raspador, Pp: Punta de proyectil, FAF: Fragmento de artefacto formatizado, Bif: Bifaz, AFS: Artefacto de formatización sumaria, Ce: Cepillo, Pe: Percutor.

\begin{tabular}{|c|c|c|c|c|c|c|c|c|c|c|c|}
\hline \multicolumn{12}{|c|}{ Terrazas } \\
\hline Localidad & DE & DI & $\mathbf{N}$ & $\mathbf{R a}$ & $\mathbf{R p}$ & Pp & FAF & Bif & AFS & Ce & $\mathbf{P e}$ \\
\hline Y. Agua Fresca & 21 & 25 & 6 & 0 & 1 & 0 & 0 & 0 & 0 & 0 & 0 \\
\hline Y. Agua Fresca- Y. Puesto Peter & 47 & 81 & 10 & 8 & 0 & 1 & 2 & 1 & 1 & 1 & 0 \\
\hline Y. Campo Indio & 11 & 24 & 3 & 0 & 0 & 0 & 0 & 0 & 0 & 0 & 0 \\
\hline Y. Dos Hermanos & 1 & 0 & 0 & 0 & 0 & 0 & 0 & 0 & 0 & 0 & 0 \\
\hline Y. Barda Las Vegas & 0 & 0 & 1 & 0 & 0 & 0 & 0 & 0 & 0 & 0 & 0 \\
\hline Y. María Inés & 13 & 11 & 0 & 2 & 0 & 0 & 0 & 0 & 0 & 0 & 0 \\
\hline Y. El Campamento & 3 & 4 & 0 & 0 & 0 & 0 & 0 & 0 & 0 & 0 & 0 \\
\hline Y. La Paz & 2 & 2 & 2 & 0 & 0 & 0 & 0 & 0 & 0 & 0 & 0 \\
\hline Y. El Cerrito & 0 & 1 & 0 & 0 & 0 & 0 & 0 & 0 & 0 & 0 & 0 \\
\hline Y. La Maggie & 0 & 0 & 0 & 0 & 0 & 0 & 0 & 1 & 0 & 0 & 1 \\
\hline $\begin{array}{l}\text { TOTAL y } \\
\%\end{array}$ & $\begin{array}{c}98 \\
34,1\end{array}$ & $\begin{array}{r}148 \\
51,5\end{array}$ & $\begin{array}{l}22 \\
7,6\end{array}$ & $\begin{array}{r}10 \\
3,4\end{array}$ & $\begin{array}{c}1 \\
0,3\end{array}$ & $\begin{array}{c}1 \\
0,3\end{array}$ & $\begin{array}{c}2 \\
0,6\end{array}$ & $\begin{array}{c}2 \\
0,6\end{array}$ & $\begin{array}{c}1 \\
0,3\end{array}$ & $\begin{array}{c}1 \\
0,3\end{array}$ & $\begin{array}{c}1 \\
0,3\end{array}$ \\
\hline
\end{tabular}


Tabla 7. Localidades muestreadas en la geoforma Cañadones discriminadas por frecuencia de clases artefactuales. Referencias: DE: Desecho externo, DI: Desecho interno, N: Núcleo; Ra: Raedera, Rp: Raspador, Pp: Punta de proyectil, FAF: Fragmento de artefacto formatizado, AFS: Artefacto de formatización sumaria, Cu: Cuchillo.

\begin{tabular}{|l|c|c|c|c|c|c|c|c|c|}
\hline \multicolumn{1}{|c|}{ Localidad } & DE & DI & N & Ra & Rp & Pp & FAF & AFS & Cu \\
\hline $\begin{array}{l}\text { Y. El Chiripá. } \\
\text { Cañadón 1 }\end{array}$ & 0 & 3 & 1 & 0 & 0 & 0 & 0 & 0 & 0 \\
\hline $\begin{array}{l}\text { Y. El Chiripá. } \\
\text { Cañadón 2 }\end{array}$ & 7 & 16 & 0 & 0 & 1 & 0 & 0 & 0 & 0 \\
\hline $\begin{array}{l}\text { Y. El Chiripá. } \\
\text { Cañadón 3 }\end{array}$ & 1 & 1 & 0 & 5 & 1 & 0 & 0 & 0 & 0 \\
\hline $\begin{array}{l}\text { Y. El Chiripá. } \\
\text { Cañadón 4 }\end{array}$ & 12 & 26 & 1 & 1 & 4 & 0 & 1 & 2 & 1 \\
\hline $\begin{array}{l}\text { Y. La Paz (Eas. La Realidad - } \\
\text { La Nueva) }\end{array}$ & 3 & 8 & 2 & 0 & 0 & 0 & 0 & 0 & 0 \\
\hline $\begin{array}{l}\text { Y.La Maggie. } \\
\text { Cañadón El Falso }\end{array}$ & 2 & 8 & 4 & 11 & 0 & 1 & 0 & 3 & 1 \\
\hline $\begin{array}{l}\text { TOTAL y } \\
\text { \% }\end{array}$ & $\mathbf{2 5}$ & $\mathbf{6 2}$ & $\mathbf{8}$ & $\mathbf{1 7}$ & $\mathbf{6}$ & $\mathbf{1}$ & $\mathbf{1}$ & $\mathbf{5}$ & $\mathbf{2}$ \\
\hline
\end{tabular}

función de la oferta de reparo y demás recursos. No obstante, si se considera la gran variabilidad interna registrada en dichas geoformas y que no existen diferencias estadísticamente significativas en cuanto a la representación de clases artefactuales, se ponen en evidencia que fueron realizadas las mismas actividades aunque con distinta intensidad.

\section{NUEVAS DATACIONES RADIOCARBÓNICAS}

Como resultado de los relevamientos llevados a cabo en la confluencia del cañadón Puesto Peter con el Brazo Norte del río Coyle (Unidad de paisaje Fondo de valles) se registra una concentración en superficie a cielo abierto de artefactos líticos y huesos

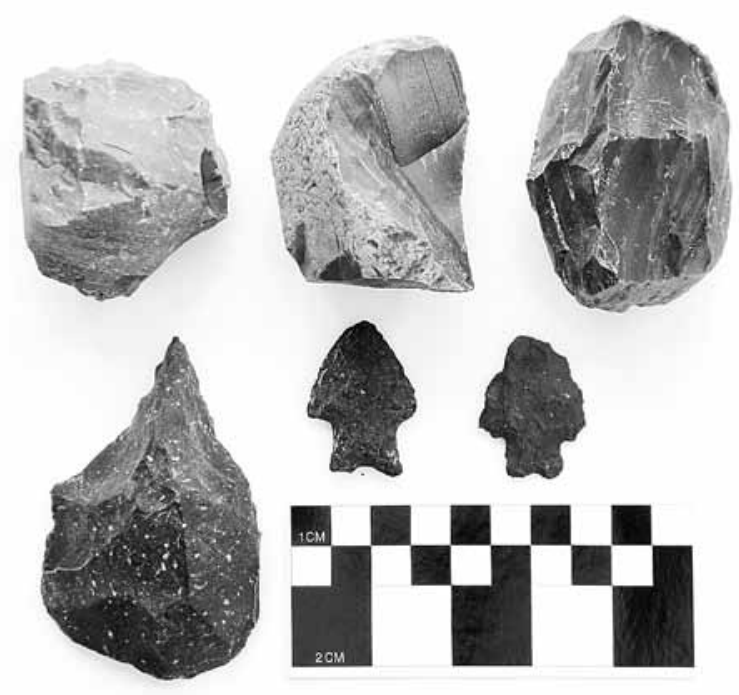

Fig. 2. Materiales recuperados en Y. Los Capones. (Ea Los Luises). Fila superior: núcleos multidireccionales con reserva de corteza en dacita. Fila inferior: perforador en dacita y puntas de proyectil Magallanes IV en RGFO.

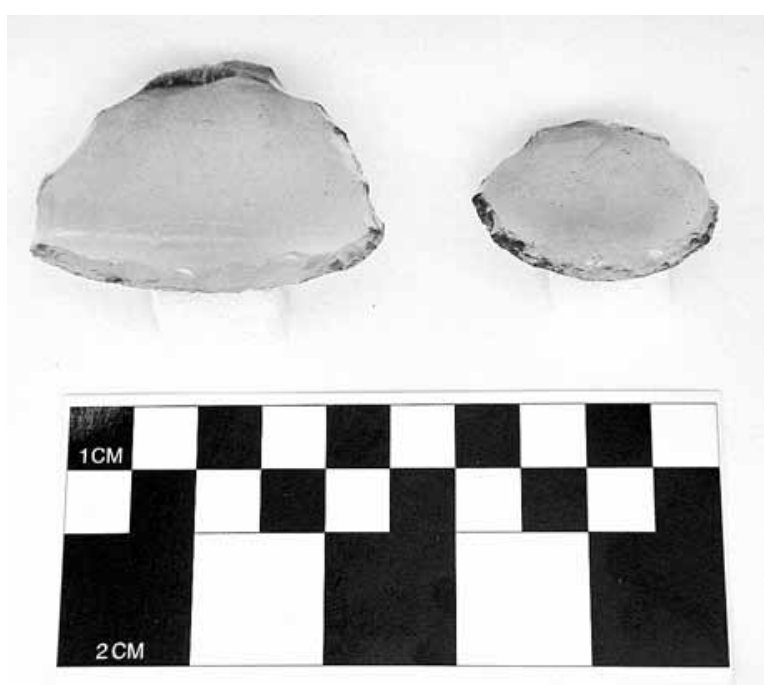

Fig. 3. Raspadores de vidrio recuperados en Y. Campo Indio. CI A 1002. 
Tabla 8. Localidades muestreadas en la geoforma Cuencas endorreicas discriminadas por frecuencia de clases artefactuales. Clases artefactuales por localidades. Referencias: DE. Desecho externo; DI: Desecho interno; N:

Núcleos; RA: Raedera; Rp: Raspador; Pp: Punta de proyectil; FAF: Fragmento de artefacto formatizado; Bif: Bifaz;

AFS: Artefacto de formatización sumaria; Cep: Cepillo; s/d: sin dato (suman 20 desechos pero no fue posible discriminar entre externo e interno), Pe: Percutor, Bo: Bola de boleadora, Cu: Cuchillo, Pf: Perforador.

\begin{tabular}{|c|c|c|c|c|c|c|c|c|c|c|c|c|c|c|}
\hline \multicolumn{15}{|c|}{ Cuencas endorreicas } \\
\hline Localidad & DE & DI & $\mathbf{N}$ & $\mathbf{R a}$ & $\mathbf{R p}$ & Pp & FAF & Bif & AFS & Ce & $\mathrm{Pe}$ & Bo & $\mathbf{C u}$ & Pf \\
\hline Y. Campo Indio. CI A 1002 & 877 & 0 & 1 & 0 & 73 & 0 & 89 & 0 & 0 & 0 & 0 & 0 & 0 & 0 \\
\hline $\begin{array}{l}\text { Y. Dos Hermanos } \\
\text { Laguna Dos Hermanos }\end{array}$ & 17 & 123 & 9 & 27 & 6 & 0 & 0 & 1 & 1 & 3 & 0 & 0 & 0 & 0 \\
\hline Y. El Chiripá (Cuenca endorreica) & 8 & 27 & 7 & 1 & 0 & 0 & 0 & 0 & 0 & 0 & 0 & 0 & 0 & 0 \\
\hline Y. El Chiripá. Bajo 1 & 16 & 2 & 3 & 9 & 1 & 0 & 0 & 0 & 0 & 0 & 0 & 0 & 0 & 0 \\
\hline Y. El Chiripá. Bajo 2 & 37 & 43 & 9 & 5 & 2 & 0 & 0 & 1 & 0 & 0 & 0 & 1 & 0 & 0 \\
\hline $\begin{array}{l}\text { Y. La Maggie. Bajo } \\
\text { Ea. La Argentina }\end{array}$ & $\mathrm{s} / \mathrm{d}$ & $\mathrm{s} / \mathrm{d}$ & 1 & 3 & 0 & 0 & 0 & 0 & 0 & 0 & 1 & 0 & 0 & 0 \\
\hline Y. La Maggie. Bajo El Barril & 1 & 6 & 2 & 0 & 0 & 0 & 0 & 1 & 0 & 0 & 0 & 0 & 0 & 0 \\
\hline Y. La Maggie. Bajo El Mate & 15 & 26 & 12 & 3 & 5 & 0 & 0 & 0 & 0 & 0 & 1 & 0 & 0 & 0 \\
\hline Y. La Maggie. Bajo del Medio & 7 & 5 & 3 & 0 & 0 & 0 & 0 & 1 & 0 & 0 & 0 & 0 & 0 & 0 \\
\hline Y. La Maggie. (Ea. Domi Aike) & 5 & 3 & 7 & 0 & 0 & 0 & 0 & 0 & 0 & 0 & 0 & 0 & 0 & 0 \\
\hline Y. Los Capones. (Ea Los Luises) & 38 & 28 & 42 & 8 & 3 & 2 & 5 & 2 & 1 & 1 & 1 & 0 & 0 & 2 \\
\hline Y. Los Capones. Bajo 1 & 26 & 40 & 13 & 19 & 12 & 1 & 1 & 3 & 1 & 3 & 2 & 0 & 2 & 0 \\
\hline Y. Los Capones. Bajo 2 & 4 & 2 & 2 & 0 & 0 & 0 & 0 & 1 & 1 & 0 & 0 & 0 & 0 & 0 \\
\hline $\begin{array}{l}\text { Y. Los Capones. Bajo } 3 \\
\text { (Ea. La Araceli) }\end{array}$ & 39 & 28 & 16 & 7 & 2 & 1 & 2 & 0 & 1 & 1 & 1 & 0 & 0 & 0 \\
\hline $\begin{array}{l}\text { Y. Los Capones. Bajo } 4 \\
\text { (Ea. La Concordia) }\end{array}$ & 14 & 19 & 3 & 4 & 1 & 1 & 3 & 0 & 0 & 2 & 0 & 0 & 0 & 0 \\
\hline Y. Los Capones. Bajo 5 & 10 & 9 & 13 & 4 & 1 & 0 & 0 & 0 & 0 & 1 & 0 & 0 & 0 & 0 \\
\hline Y. Los Capones. Bajo 6 & 32 & 57 & 4 & 20 & 4 & 1 & 3 & 0 & 2 & 1 & 0 & 0 & 0 & 0 \\
\hline Y. Los Capones. Bajo 7 & 36 & 51 & 32 & 16 & 5 & 1 & 2 & 1 & 1 & 1 & 0 & 0 & 3 & 0 \\
\hline $\begin{array}{l}\text { Y. Los Capones. Bajo } 8 \\
\text { (Ea. Ototel Aike) }\end{array}$ & 5 & 5 & 5 & 1 & 0 & 0 & 0 & 0 & 0 & 0 & 0 & 0 & 0 & 0 \\
\hline $\begin{array}{l}\text { Y. Los Capones. Bajo } 9 \\
\text { (Ea. Los Alamos) }\end{array}$ & 10 & 2 & 17 & 0 & 0 & 0 & 0 & 0 & 0 & 0 & 0 & 0 & 0 & 0 \\
\hline $\begin{array}{l}\text { TOTAL y \% } \\
\text { (con vidrio) }\end{array}$ & $\begin{array}{l}2272 \\
52,6\end{array}$ & \begin{tabular}{|l|}
474 \\
20,8
\end{tabular} & $\begin{array}{l}201 \\
8,8\end{array}$ & $\begin{array}{l}127 \\
5,5\end{array}$ & $\begin{array}{c}115 \\
5,06\end{array}$ & $\begin{array}{c}7 \\
0,3\end{array}$ & $\begin{array}{l}105 \\
4,6\end{array}$ & $\begin{array}{l}11 \\
0,4\end{array}$ & \begin{tabular}{|c|}
8 \\
0,3
\end{tabular} & $\begin{array}{c}13 \\
0,5\end{array}$ & $\begin{array}{c}6 \\
0,2\end{array}$ & $\begin{array}{c}1 \\
0,04\end{array}$ & $\begin{array}{c}5 \\
0,2 \\
\end{array}$ & $\begin{array}{c}2 \\
0,08\end{array}$ \\
\hline $\begin{array}{l}\text { TOTAL y \% } \\
\text { (sin vidrio) }\end{array}$ & 26,01 & 38,4 & 16,2 & 10,2 & 3,4 & 0,5 & 1,2 & 0,8 & 0,6 & 1,05 & 0,4 & 0,08 & 0,1 & \\
\hline
\end{tabular}

Tabla 9. Fechados radiocarbónicos de la cuenca media del río Coyle. * Asociado con un alambre. ***

Diáfisis con huellas de corte y negativos de lascados. ${ }^{* * *}$ Epífisis distal con marcado perimetral.

\begin{tabular}{|c|c|c|c|c|c|}
\hline Localidad / sitio & Material & $\begin{array}{c}\text { Fechado } \\
\text { (años AP) }\end{array}$ & $\begin{array}{c}\mathbf{d}^{\mathbf{1 3} \mathbf{C}} \\
\text { (colágeno) }\end{array}$ & Laboratorio & Referencia \\
\hline Camusu Aike & Caballo (Equus caballus) & Moderno & --- & LATyR & Carballo Marina et al. 2000-2002 \\
\hline Las Horquetas & Costilla humana & $\leq 200$ años & $-21,61$ & LATyR & $\begin{array}{c}\text { Carballo Marina et al. 2000-2002, } \\
\text { Barberena 2002 }\end{array}$ \\
\hline Puesto Peter & $\begin{array}{c}\text { Radiocúbito de guanaco } \\
\text { (Lama guanicoe)** }^{* *}\end{array}$ & $304 \pm 44$ & $-20,2$ & AA-86452 & Este trabajo \\
\hline Ea. El Zorro & Diente humano & $305 \pm 46$ & $-19,4$ & AA-86451 & Este trabajo \\
\hline Las Horquetas & Fémur de guanaco**** & $1660 \pm 60$ & --- & AA-47339 & Belardi et al. 2006 \\
\hline
\end{tabular}


de guanaco (Lama guanicoe). Se dató una diáfisis de radiocúbito que presentaba huellas de corte y un golpe lateral y un premolar humano producto de la recolección asistemática de un esqueleto hallado al construir un molino en Ea. El Zorro, en inmediaciones del Yacimiento Los Capones (Tabla 9 y Fig. 1). Ambas dataciones corresponden a momentos históricos y se suman a la escasa información cronológica disponible para la cuenca media del río Coyle (Carballo Marina et al. 2000/2002). Por otra parte, el análisis del diente humano aporta un nuevo valor isotópico - en relativa cercanía a la costa $(\sim$ $50 \mathrm{~km}$ )- que también indica una dieta continental (ver Barberena 2002).

\section{CONCLUSIONES}

Las dataciones radiocarbónicas previas sitúan el uso humano de la cuenca media del río Coyle al menos en el Holoceno tardío, mientras que las ahora presentadas se ajustan a lo ya conocido para las poblaciones cazadoras recolectoras en momentos del contacto (ver Martinic 1995; Peláez y Jimenez 2006). Más allá de esto, la mayor profundidad temporal de las ocupaciones de la costa -ca. 5100 años AP- (Caracotche et al. 2005; Cruz et al. 2010; Muñoz et al. 2009) y del oeste de la cuenca del río Coyle -ca. 4500 años AP- (Borrero et al. 2006; Borrazzo 2008) permiten postular el uso humano de la cuenca media desde momentos más tempranos. No obstante, como indican los autores recién mencionados, tanto en la costa como en el interior la señal cronológica más destacada es eminentemente tardía (últimos 2000 años AP).

La nueva evidencia sobre la cuenca media del río Coyle profundiza resultados previos. Así, se explora la distribución espacial del registro arqueológico considerando las tres geoformas que caracterizan a la unidad de paisaje Terrazas: terrazas, cañadones y cuencas endorreicas. El análisis se focaliza sobre las densidades y clases artefactuales y las materias primas líticas empleadas para la talla. En primer lugar, se reafirma la baja intensidad de uso del espacio regional, ya que los valores de densidad artefactual corresponden a órdenes de magnitud de $10^{-4}$. No obstante, existe una gran variabilidad interna en cada geoforma, ya que los coeficientes de variación también son muy grandes. Esto último indica diferencias marcadas en cuanto a las intensidades de uso de espacios específicos. El comportamiento de las variables analizadas es homogéneo, por lo que no hay representación diferencial ni de rocas ni de clases artefactuales por geoforma. Esta situación se repite aún considerando por separado al vidrio. Por lo tanto, el registro arqueológico indica que en las distintas geoformas se habrían desarrollado los mismos tipos de actividades, las que se relacionarían con el aprovisionamiento de materias primas y actividades de talla. Ahora, si se consideran las diferencias registradas en los valores de las densidades artefactuales se ve que dichas actividades difirieron en su intensidad. Aquí, se destacan las cuencas endorreicas. Si bien la variabilidad interanual en la disponibilidad de agua es significativa, se posicionan como puntos del espacio de uso más recurrente también asociado al reparo y a la disponibilidad de rocas aptas para la talla. Sobre la base de la información paleoambiental generada en la laguna Potrok Aike -que indica condiciones más secas y menos frías para los últimos 1600 años (ver Fey et al. 2009)- se plantea que la diferente provisión de agua en las cuencas endorreicas habría contribuido con la alta variabilidad interna observada en las densidades artefactuales.

La evidencia de moluscos de procedencia atlántica -Nacella magellanica y Mytilus edulisrecuperada en contextos arqueológicos del interior ( $35 \mathrm{~km})$ reafirma la interacción con los espacios costeros. Además, el hallazgo previo de un ejemplar de Panopea abbreviata sostiene esta interacción a grandes distancias ( $400 \mathrm{~km}$ ) (Carballo Marina et al. 2000-2002). La presencia de bajas frecuencias de artefactos de obsidiana indica que dicha roca también habría sido incorporada -si bien sólo marginalmente- dentro de los circuitos de circulación de bienes e información. La misma situación es referida para la costa del Parque Nacional Monte León (Caracotche et al. 2005). A la vez, en Punta Entrada -sobre la margen sur de la desembocadura del río Santa Cruz- se registra un artefacto sobre asta de huemul (Hippocamelus bisulcus) que también señala contactos con espacios ubicados al oeste (Cruz et al. 2010). En este escenario, en la cuenca media del río Coyle se documenta el diseño de puntas de proyectil Magallanes IV -confeccionadas mayoritariamente sobre RGFO- (Belardi et al. 2006; Carballo Marina et al. 2000-2002), semejante al descripto para el espacio comprendido entre el norte del río Santa Cruz y el norte del estrecho de Magallanes 
(cf. Franco et al. 2010a). Así, se suma una región intermedia a la discusión sobre la circulación de un modelo exitoso de punta de proyectil durante el Holoceno tardío (Franco et al. 2010a).

Se pueden plantear diferencias en términos del uso del espacio entre la costa y el interior. La costa presenta mayor diversidad y densidades artefactuales (Belardi et al. 2006, Borrero et al. 2008; Caracotche et al. 2005; Franco et al. 2010b y, por lo tanto, parece haber sido utilizada más intensamente; aunque siempre empleando los mismos tipos y proporciones de materias primas líticas y tipos artefactuales que en el interior. Observaciones preliminares en derredor de Puerto Coyle (margen norte de la desembocadura del río Coyle) también sustentarían la propuesta.

Por último, se destaca la continuidad tecnológica en la manufactura de raspadores, pero con el empleo del vidrio. Además, a partir de la introducción de esta materia prima se ve un cambio en la jerarquización de artefactos: donde antes dominaban las raederas ahora lo hacen los raspadores. Esto, ya observado en trabajos anteriores (Carballo Marina et al. 2000-2002; ver Gómez Otero 1998), se ve reforzado con los hallazgos del Yacimiento Campo Indio, en el sitio CI A 1002, que se relacionan con la ocupación de la reserva Tehuelche de Camusu Aike.

El paisaje arqueológico de la unidad de paisaje Terrazas se corresponde con el generado por una alta movilidad residencial. Esto concuerda con la distribución relativamente homogénea de recursos y con el bajo riesgo climático invernal (Borrelli et al. 1997). Así, puede pensarse que el amplio espacio relevado respondería a situaciones de uso continuo pero de baja intensidad más relacionado con la circulación de poblaciones humanas hacia y entre las cuencas fluviales del Santa Cruz y del Gallegos. Este patrón recién habría cambiado en momentos históricos, donde la incorporación del caballo redujo la movilidad residencial (ver Goñi 2000). Luego, la confinación en reservas como la de Camusu Aike termina de quebrar los patrones de movilidad con efectos determinantes sobre la continuidad social y biológica de las poblaciones cazadoras recolectoras. El espacio que fue principalmente de circulación se convierte en el lugar de residencia permanente.

La reafirmación de los patrones reconocidos indica que la búsqueda de variabilidad regional, más allá de la detectada en Fondo de valles y en la costa atlántica, se deberá orientar hacia nuevas variables. La preeminencia del material lítico señala que la misma deberá ser de carácter tecnológico y de mayor especificidad que la sola representación de materias primas y tipos artefactuales. Es necesario explorar más intensamente tanto hacia la cuenca superior como hacia la costa y obtener mayores precisiones cronológicas.

\section{AGRADECIMIENTOS}

A Dora Maglione por su asesoramiento informático estadístico, a Susana Pittaluga por las determinaciones malacológicas, a Daniel Grima por la confección del mapa y a Pedro Tiberi por atender nuestras consultas sobre geología regional.

Asimismo, agradecemos a Javier Vallejo Andrade, Patricia Campan y Cecilia Pallo la ayuda brindada durante los trabajos de campo.

A la familia Halliday (Ea. El Zorro) por facilitarnos muestras para el estudio.

Por último, a Patricia Madrid, Luis Borrero y a un revisor anónimo por la lectura crítica del manuscrito y sus valiosos comentarios.

\section{BIBLIOGRAFÍA}

ARAGÓN, E. y N. FRANCO 1997. Características de rocas para la talla por percusión y propiedades petrográficas. Anales del Instituto de la Patagonia Serie Cs. Humanas, Punta Arenas, 25:187-199.

ASCHERO, C. 1983[1975]. Ensayo para una clasificación morfológica de artefactos líticos. MS.

BARBERENA, R. 2002. Los límites del mar. Isótopos estables en Patagonia meridional. Sociedad Argentina de Antropología. Colección Tesis de Licenciatura. Buenos Aires. BELARDI, J. B., P. TIBERI, C. STERN y A. SÚNICO 2006. Al este del cerro Pampa: ampliación del área de disponibilidad de obsidiana de Pampa del Asador (Provincia de Santa Cruz). Intersecciones en Antropología 7: 27-36.

BELARDI, J.B., F. CARBALLO MARINA y S. ESPINOSA 2006. Cazadores recolectores en la cuenca media e inferior del río Coyle. En: La cuenca del río Coyle. Estado actual de las investigaciones. Editado por Belardi J.B., Carballo Marina F. y S. Espinosa, pp. 97-128. Universidad Nacional de la Patagonia Austral. Río Gallegos.

BINFORD, L.R 1980. Willow Smoke and Dog's Tails: HunterGatherer Settlement Systems and Archaeological Site Formation. American Antiquity, 45:4-20. 
BIRD, J. 1988. Viajes y arqueología en Chile Austral. Editado por J. Hyslop. Ediciones de la Universidad de Magallanes. Punta Arenas.

BORRAZZO, K. 2008. Análisis tecnológico de distribuciones artefactuales en la periferia Sudeste de la Sierra Baguales (Santa Cruz, Argentina). Magallania, 36(1):103-116.

BORRELLI, P., G. OLIVA, M. WILLIAMS, L. GONZÁLEZ, P. RIAL y L. MONTES 1997. Sistema regional de soporte de decisiones. Santa Cruz y Tierra del Fuego. Prodesar (INTA-GTZ). EEA Santa Cruz. Río Gallegos.

BORRERO, L., R. BARBERENA, N. FRANCO, F. MARTIN, S. CARACOTCHE, L. MANZI J. CHARLIN y K. BORRAZZO 2008. Plan de monitoreo del registro arqueológico del Parque Nacional Monte León. La información de superficie. En: Arqueología de la costa patagónica. Perspectivas para la conservación. Editado por Caracotche S. y I. Cruz, pp. 161-172. UNPA, Subsecretaría de Cultura de La Provincia de Santa Cruz. Río Gallegos.

BORRERO, L.A. 2001. El poblamiento de la Patagonia. Toldos, milodones y volcanes. Emecé Editores, Buenos Aires.

BORRERO, L.A., N.V. FRANCO, F.M. MARTIN, R. BARBERENA, R. GUICHÓN, J.B. BELARDI, C. FAVIER DUBOIS y G.L. L'HEUREUX 2006. Las Cabeceras del Coyle: información arqueológica y circulación de poblaciones humanas. En: La cuenca del río Coyle. Estado actual de las investigaciones. Editado por Belardi J. B., F. Carballo Marina y S. Espinosa, pp. 75-95. Universidad Nacional de la Patagonia Austral. Río Gallegos.

CÁCERES, A.P. y J. CABALLERO 2006. Consideraciones generales sobre la cuenca del río Coyle o Coig. En: $L a$ cuenca del río Coyle. Estado actual de las investigaciones. Editado por Belardi J. B., F. Carballo Marina y S. Espinosa, pp. 21-28. Universidad Nacional de la Patagonia Austral. Río Gallegos.

CARACOTCHE, M.S., I. CRUZ, S. ESPINOSA, F. CARBALLO MARINA y J.B. BELARDI 2005. Rescate arqueológico en el Parque Nacional Monte León (Santa Cruz, Argentina). Magallania, 33(2):143-163.

CARBALLO MARINA, F., J.B. BELARDI, S. ESPINOSA y B. ERCOLANO 2000-2002. Tecnología y movilidad en el río Coyle, Santa Cruz. Cuadernos del Instituto Nacional de Antropología y Pensamiento Latinoamericano, 19:89-107.

CHARLIN, J. 2005. Aprovisionamiento de materias primas líticas en el campo volcánico de Pali Aike (Santa Cruz): una primera aproximación a partir del análisis de los núcleos. Werken, 7(2):39-55.

CRUZ, I., A.S. MUÑOZ y M.S. CARACOTCHE 2010. Un artefacto en asta de huemul (Hippocamelus bisulcus) en depósitos arqueológicos de la costa atlántica. Implicaciones para la movilidad humana y la distribución de la especie. Magallania, 38(1):287-294.

CUADRA, D. y G. OLIVA 1996. Ambientes naturales de la provincia de Santa Cruz. Espacios, 6:22-27.

DIÉGUEZ, M.C. 2003. Estructura y composición de la comunidad pelágica de lagunas efímeras y mallines de la Patagonia Norte: aspectos generales y particulares de ambientes andinos y extraandinos. En: Resúmenes II Jornadas patagónicas de Mallines y Humedales Universidad Nacional de la Patagonia Austral. Unidad Académica Río Gallegos, pp. 30. Río Gallegos.

ESPINOSA, S. y R. GOÑI 1999. Viven!! Una fuente de obsidiana en la provincia de Santa Cruz. En: Soplando en el viento. Actas de las III Jornadas de Arqueología de la Patagonia. Editado por el Instituto Nacional de Antropología y Pensamiento Latinoamericano y la Universidad Nacional del Comahue, pp. 177-188. San Carlos de Bariloche.

ESPINOSA, S., J. B. BELARDI y F. CARBALLO MARINA 2000. Fuentes de aprovisionamiento de materias primas líticas en el sector inferior del interfluvio Coyle - Gallegos (Depto. Guer Aike, provincia de Santa Cruz). En: Desde el País de los Gigantes. Perspectivas arqueológicas en Patagonia. Universidad Nacional de La Patagônia Austral. Tomo I, pp: 5-17. Rio Gallegos.

FEY, M., C. KORR, N.I. MAIDANA, M.L. CARREVEDO, H. CORBELLA, S. DIETRICH, T. HABERZETTL, G. KUHN, A. LÜCKE, C. MAYR, C. OHLENDORF, M. M. PÁEZ, F. QUINTANA, F. SCHÄBITZ y B. ZOLITSCHKA 2009. Paleoenvironmental changes during the last 1600 yers inferred from the sediment record of a cirque lake in southern Patagonia (Laguna Las Vizcachas, Argentina). Palaeogeography, Palaeoclimatology, Palaeoecology, 281:363-375.

FIDALGO, F. y J.C. RIGGI 1970. Consideraciones geológicas y sedimentológicas sobre los Rodados Patagónicos. Revista Asociación Geológica Argentina, XXV (4):430-443.

FOLEY, R. 1981. Off-site archaeology: an alternative approach for the short-sited. En: Pattern of the Past: Studies in Honour of David Clarke. Editado por I. Hoder, G. Isaac y N. Hammond, pp. 157-183. Cambridge University Press, Cambridge.

FRANCO, N.V., J. GÓMEZ OTERO, G. GURAIEB, S. GOYE, N. CIRIGLIANO y A. BANEGAS 2010a. Variaciones espaciales en diseños de puntas pedunculadas medianas en Patagonia argentina: una nueva aproximación. En: Arqueología argentina en el bicentenario de la Revolución de Mayo. XVII Congreso Nacional de 
Arqueología Argentina. Editado por Bárcena J.R. y H. Chiavazza, Tomo 1:281-286. Facultad de Filosofía y Letras UNCuyo e Instituto de Ciencias Humanas, Sociales y Ambientales. CONICET. Mendoza.

FRANCO, N.V., M.A. ZUBIMENDI, M. CARDILLO y A.L. GUARIDO 2010b. Relevamiento arqueológico en cañadón de los Mejillones (sur de la desembocadura del río Santa Cruz, Argentina): primeros resultados. Magallania, 38(1):269-280.

GÓMEZ OTERO, J. 1998. Rescate y reinserción de las capas de cuero (quillangos) de los aborígenes de Patagonia en la provincia del Chubut, Argentina. Cuadernos del Instituto Nacional de Antropología, XVII: 69-87.

GOÑI, R.A. 2000. Arqueología de momentos históricos fuera de los centros de conquista y colonización: un análisis de caso en el sur de Patagonia. En: Desde el País de los Gigantes. Perspectivas Arqueológicas en Patagonia. Editado por la Universidad Nacional de la Patagonia Austral, I: 283-296. Río Gallegos.

HABERZETTL, T., M. FEY, A. LUCKE, N. MAIDANA, C. MAYR, C. OHLENDORF, F. SCHABITZ, G. H. SCHELESE, M. WILLE y B. ZOLITSCHKA 2005. Climatically induced lake level changes during the last two millenia as reflected in sediments of Laguna Potrok Aike, southern Patagonia (Santa Cruz, Argentina). Journal of Pelolimnology, 33:283-302.

MARTINIC, B.M. 1995. Los Aónikenk. Historia y Cultura. Ediciones de la Universidad de Magallanes. Punta Arenas.

MAZZONI, E. y M. VÁZQUEZ 2001. Evaluación de pastizales húmedos para un aprovechamiento sustentable en la cuenca del río Gallegos (Provincia de Santa Cruz, Argentina). En: VIII Encuentro Latinoamericano de Geógrafos, pp: 175-182. Santiago de Chile.

MAZZONI, E., M. VÁZQUEZ, J.B. BELARDI, C. ALBRIEU, F. CARBALLO MARINA, S. ESPINOSA, J. LARROSA y
D. GISMONDI 1999. Las cuencas endorreicas o "Bajos sin salida". Consideraciones acerca del estudio de una de las geoformaciones típicas del paisaje patagónico. Espacios, 16:45-50.

MUÑOZ, A.S., M.S. CARACOTCHE y I. CRUZ 2009. Cronologia de la costa al sur del rio Santa Cruz: nuevas dataciones radiocarbónicas en Punta Entrada y Parque Nacional Monte León (Provincia de Santa Cruz, Argentina). Magallania, 37(1):193-197.

NELSON, M.C. 1991. The Study of Techonological Organization. En: Archaeological Method and Theory. Editado por Schiffer M., 3:57-100. The University of Arizona Press, Tucson.

OLIVA, G., L. GONZÁLEZ, P. RIAL y E. LIVRAGHI 2001. El ambiente en la Patagonia Austral. En: Ganadería ovina sustentable en la Patagonia Austral. Tecnología de Manejo Extensivo. Editado por Borrelli P. y G. Oliva, pp. 19-82. Ediciones Instituto Nacional de Tecnología Agropecuaria. Buenos Aires.

PELÁEZ, P.A. y L. JIMÉNEZ 2006. Los viajeros en el Coy. La cuenca del río Coyle. En: La cuenca del río Coyle. Estado actual de las investigaciones. Editado por. Belardi J. B, F. Carballo Marina y S. Espinosa, pp. 129-164. Universidad Nacional de la Patagonia Austral. Río Gallegos.

STERN, C. 1999. Black Obsidian from Central-South Patagonia: chemical characteristics, sources and regional distribution of artifacts. En: Soplando en el viento. Actas de las III Jornadas de Arqueología de la Patagonia. Editado por el Instituto Nacional de Antropología y Pensamiento Latinoamericano y la Universidad Nacional del Comahue, pp.221-234. San Carlos de Bariloche.

STERN, C. y N.V. FRANCO 2000. Obsidiana gris verdosa veteada de la cuenca superior del Santa Cruz, extremo sur de Patagonia. Anales del Instituto de la Patagonia. Serie Ciencias Humanas, 28:265-273. 